\title{
versants
}

\section{El giro afectivo en las canciones de El hombre acecha}

\author{
Laura SCARANO \\ Universidad Mar del Plata/CONICET \\ ORCID: 0000-0002-I417-3004
}

\begin{abstract}
Miguel Hernández es un poeta inequívocamente político e incuestionablemente íntimo. «Canción primera» y «Canción última», prólogo y epílogo de El hombre acecha, son una inmejorable muestra de esta profunda imbricación, que adelanta el giro afectivo del Cancionero y Romancero de ausencias. La elección del molde retórico de la canción no es inocente, ya que responde a un proyecto de ideologización de los formatos y metros tradicionales, clave en su perspectiva autorreferencial. Supone una postura de apropiación y distancia, homenaje y réplica en el interior mismo de la activa tradición literaria. Este giro afectivo consolida un itinerario con resonancias civiles que va profundizando una voz introspectiva y autoanalítica. Su arte poética, en este libro como en toda su obra, revela una aguda consciencia de su mester, y la elección de moldes estróficos para muchos de sus paratextos representa una instancia inmejorable para reafirmar su conciencia metaliteraria.
\end{abstract}

Keywords: Miguel Hernández, canción, giro afectivo, autorreferencia.

... te escribo con la imborrable tinta de mi sentimiento...

«Carta» [¿referencia?]

Hace ya unos cuantos años se ha introducido en el análisis de los discursos sociales el llamado "giro afectivo» (the affective turn) para denotar un espacio que, más allá de los géneros artísticos específicos, señala un repliegue en lo privado y emocional, coincidente con lo que otros críticos llaman «giro subjetivo» o «giro autobiográfico». En ciertas tipologías literarias, que oscilan entre el testimonio y la ficción, ha ganado terreno esta notoria incidencia en la intimidad y la evidente disolución de las esferas antaño antinómicas entre lo público y lo privado. Pero esto no es privativo del nuevo siglo, mucho menos en el género lírico. En otros trabajos me he dedicado especialmente al estudio de esta interacción entre poesía y experiencia (erlebnis) ${ }^{1}$, y cómo, desde varias modulaciones teóricas como la llamada Semiótica de las pasiones o la Teoría de los afectos, se nos posibilitan instrumentos no solo para renovar nuestra mirada sobre el imaginario poético actual, sino

I Un primer estudio sobre la intimidad y sus rituales en el discurso literario fue publicado en mi libro Palabras en el cuerpo. Literatura y experiencia (Scarano 2007). Y desarrollé un pormenorizado estado de la cuestión teórica en el artículo de la revista Telar (Scarano 20II). 
para ensayar nuevas aproximaciones a legados anteriores, superados ya los temores a las lecturas meramente genéticas o forzadamente biografistas. El interés teórico por los afectos procede pues de larga data, pero «el giro afectivo se produce a mediados de los 90, desde varios campos de investigación transdisciplinarios» (Del Sarto 20I2: 43).

Por otro lado, si bien la traslación del prefijo meta al terreno de las artes y la literatura resulta tardía en relación a la lógica, las matemáticas o las ciencias del lenguaje, el siglo xx entronizó la galaxia metaficcional y la diseminó en todos los géneros artísticos como un eje axial de construcción discursiva. Roland Barthes en sus Ensayos críticos aplica la noción de metalenguaje, usada antes por Roman Jakobson y tomada de la lógica, para hablar de metaliteratura. A pesar de la ambigüedad producida por su uso, parece haberse consolidado plenamente como ya dijimos el término metaficción, para denominar un universo cuyo principio constructivo se apoya en la noción de autorreferencia ${ }^{2}$. El prefijo auto señala a nuestro juicio de manera más acabada el repliegue autoconsciente que el más vago de meta ${ }^{3}$. En el orbe conceptual de la metaficción y autorreferencia, la categoría de metapoesía es la que presenta mayor atraso teórico, como ya lo hemos analizado in extenso en otros trabajos (Scarano 20I7).

Una mirada atenta a la poesía de Miguel Hernández con estos renovados instrumentos teóricos echa luz sobre una de las innovaciones más destacadas del poeta de Orihuela: las duplas privado-público, social-individual, sentimiento-artificio aparecen como posiciones no enfrentadas, necesariamente articuladas tanto en la vida histórica como en el discurso literario. Y la prueba de su autoconciencia se afinca en su lúcida "poética de autor", que supera los postulados al uso del realismo socialista con pocas pero contundentes afirmaciones, como las vertidas en el breve texto en prosa de 1933 titulado "Mi concepto del poema», del que podemos extraer una fecunda secuencia: «¿Qué es el poema? Una bella mentira fingida», «una verdad insinuada», para afirmar como corolario: «una verdad tan verdadera que no se

2 En los tempranos años 9o, el libro La voz diseminada. Hacia una teoría del sujeto en la poesía española (1994), que publicamos con Marcela Romano y Marta Ferrari, pretendió dar un marco teórico riguroso a la especulación metapoética, desde una insularidad argentina que por aquellas épocas hacía muy difícil el acceso a las fuentes extranjeras en general. Incursionamos en un uso pionero del término autorreferencia lírica dos años después en el libro Marcar la piel del agua. La autorreferencia en la poesía española contemporánea (Scarano, Romano, Ferrari 1996), donde cuestionamos los usos reductivos del término y apuntamos a una comprensión no solo retórica, sino sociológica e histórica del fenómeno. Además de una docena de artículos y capítulos al respecto, vuelvo a esta cuestión en un capítulo de La poesía en su laberinto. AutoRepresentacioneS\#I (Scarano 2013).

3 Es posible especular que se haya impuesto más el prefijo meta que auto, con el término metaficción, por su derivación directa de metalenguaje, propuesto por Jakobson en su célebre clasificación de las funciones del lenguaje, para designar los mensajes que centran su significado en el propio código lingüístico que utilizan. 
ve, pero se sabe». Si bien estas afirmaciones las hace cuando aún se esfuerza por escribir en clave vanguardista, ya se avizora su convicción de que ese saber involucra asimismo un sentir poético decisivo, porque concluye «¿Cuánto dirá el poeta con el poema incorporado a sus dedos?» (I992: II, 2II3), es decir, que apuesta sin lugar a dudas por una poética corporal y sensitiva. En la segunda parte de otro texto teórico («Fórmulas»), que titula «(De Poesía)», subraya este proceso que va de la recolección de «sensaciones», «hervores de gozo y agonía» como «suceso interno y continuo» a volcarlo «al recipiente -y músico del verso formal», «después de lo cual puede servirlo» y derramarlo hacia los demás (I992: II, 2I25).

Focalizo aquí esta cuestión, que involucra su poética con el giro afectivo, especialmente en El hombre acecha, sin ignorar la anterior flexión neorromántica y sus vertientes metapoéticas como una más de las facetas del versátil vanguardismo de Hernández. Pero me detengo en su énfasis en afirmar su identidad a través de la intersubjetividad, en trazar una retórica de la afectividad que no soslaya la dimensión política e histórica ni el sustrato autobiográfico, pero que construye una voz coral que reemplaza el solipsismo del yo metapoético tradicional por una apuesta anclada en la tradición lírica colectiva, lo que da cuenta de una subjetividad vinculada y verbalizada, afincada en los afectos. Como bien afirma Joaquín Marco Hernández, Hernández se limita a «construir una ficción: la de la comunidad poética» (I993: I45). Justamente en este libro, en el poema autorreferencial «Llamo a los poetas», ratifica que el locus de su voz es la tierra y «la emoción del día», espantando el fantasma de «mi corazón helado en varios tomos». Una voz en plural recupera la tradición lírica, pero insta a los poetas a «transparentar los cuerpos» (404).

Nuestra propuesta es releer desde este ángulo algunos poemas catalogados por el autor como "canción», que confirman uno de sus formatos retóricos preferidos. La canción, en su amplia tradición culta y popular, le permite exhibir una armónica convivencia entre lo que he llamado en otro trabajo «identidad social e intimidad sentimental»(Scarano 20Io), pero además exhibe su preocupación por la forma. En estos casos, el título es el metro, un molde retórico que conlleva toda una tradición. Como bien ha señalado la crítica, la «poesía en la guerra» hernandiana no solo retoma el romance, «forma espontánea de la comunicación republicana, del yo y del grupo», potenciando su carácter oral y recitativo, como instrumento de combate, sino también la canción lírica más depurada, que -en palabras de Agustín Sánchez Vidal- «tiene precedentes muy remotos en unas coplas flamencas que compone en su adolescencia y alcanza sus momentos culminantes en las canciones neopopularistas», desde Quién te ha visto y quién te ve hasta el Cancionero (I992: 87). Ya ha destacado Juan Cano Ballesta el «uso exclusivamente lírico de estrofas de carácter tradicional», entre la copla y la canción (2004: 
I2I). Aullón de Haro también ha insistido en el peso de la constelación léxica de «canto/cantar» en sus «ideas teórico-literarias» y en las formas presentes en su obra, desde Perito en lunas hasta el Cancionero (1993: 260). Leopoldo de Luis y Jorge Urrutia (1982) o Rovira (1993) han estudiado las huellas de los cancioneros tradicionales en su obra; incluso destacan variantes de versos de cantares populares reescritos casi literalmente. José María Padilla Valencia (1999) estudia los aspectos polimétricos de su obra y subraya el uso popular de versos de arte menor, especialmente el octosílabo y heptasílabo. Mariapía Lamberti destaca la atención primaria del poeta hacia las formas métricas acordes con su sentir poético y analiza su evolución hasta decantar el verso alejandrino en los heptasílabos, que confirman el repliegue a formas más breves en su poesía última (I993: 669).

La tradición de la canción popular constituye una modalidad muy dúctil de poesía condensada y breve, con rima asonante y metros cortos, que se suele dividir en dos grupos: la canción «culta» (con una vertiente italiana petrarquista, cultivada y renovada en el contexto áureo español; y otra vertiente española de origen medieval -trovadoresca-, vinculada a la tradición aristocrática y a la «gaya ciencia»), y la canción «tradicional», ligada a la oralidad ${ }^{4}$. Los clásicos del Siglo de Oro usaron la canción libre o silva con rima consonante y versos endecasílabos y heptasílabos; llegará renovada al romanticismo (Bécquer, Espronceda) y a los modernistas y vanguardistas, con un rico abanico de tonos en Rubén Darío, Antonio Machado, Juan Ramón Jiménez, Federico García Lorca y Rafael Alberti, basando su efecto poético en la impresión y sugerencia. Desde los «dezires y layes» del nicaragüense a los ligeros acordes neopopularistas del poeta de Moguer y los cantares y proverbios de Machado, pasará a los tonos festivos del Marinero en tierra o los ribetes angustiosos de Sobre los ángeles de Alberti, hasta desembocar en los dinámicos enlaces de ritmo y narración en el Lorca de Canciones (Leuci 2009: s/p). Estudia Ana Suárez Miramón esta tradición y advierte su profusión en los años 20 y 30 del siglo xx, llegando a afirmar que «se puede hablar de una verdadera poesía de cancionero» en donde estos poetas concentran su trayectoria lírica y devenir íntimo (1993: 643).

\footnotetext{
4 La canción tradicional en el contexto español implica, para Margit Frenk, hablar de «la lírica que pertenece al pueblo y a su cultura» y que desde la Edad Media se plasmaba en cantares «de carácter eminentemente rural [cantados] durante sus labores diarias, en sus ratos de ocio y en sus fiestas", "transmitidos de boca en boca, de generación en generación, en un proceso de variación dinámico» (2006: I2). Se trata de un complejo itinerario, por el cual «en la civilización occidental la canción sigue un largo derrotero -que reconoce raíces grecolatinas y orientales más antiguas- a través fundamentalmente del canto llano de la Edad Media, las representaciones de teatro sacro y profano, las cantilenas, las canciones de parranda de los siglos IX y x, los carmina goliardescos, las pastorales, las canciones trovadorescas (s. XI a XIV), las canzoni, liedlein y frottole de los siglos XV y XVI, etc.» (Rivera y Ford I97I: 73).
} 
Esta canción tradicional de versátiles contornos y legados múltiples es la corriente que más inspirará a Hernández y resulta un programa poético per se. Darío Puccini afirma que la tradición cancioneril es «una tonalidad y una forma poética original en el tratamiento que le da Hernández, porque se configura como una manera entre festiva y seria, entre musical e iterativa, entre un tipo de brevedad seguramente clásica y un fragmentarismo vanguardista» (Hernández 1993: 120). Y ya Carlos Bousoño notó en I960 que «Hernández supo escribir un libro de canciones sin parecerse nada a Lorca ni a Alberti», especialmente por decantarlo y «hacerlo sentir como manifestación autobiográfica» (33). Sin duda, «la apropiación del acervo popular que el poeta oriolano lleva a cabo entraña mucho más una revitalización y una ponderación crítica de las formas tradicionales, que una práctica poética neutra, alienada o meramente formulaica» (Riva 20I5: 328). Es así como «Hernández traza una retórica familiar a la oralidad, en la que conviven las formas menudas de la tradición octosilábica con los versos hímnicos de largo aliento». Se produce, entonces, «el pasaje de lo "tradicional" colectivo al repertorio de lo "tradicional" incrustado en la escena de la intimidad" (Riva 2014:390).

Las dos canciones que abren El hombre acecha (1937-1939), uno de los libros más combativos de Miguel Hernández, nos permite constatar que se produce aquí un «recogimiento del poeta hacia un nuevo intimismo, replegando velas, tras el clímax de Viento del pueblo, a unas secuencias claramente anticlimáticas, que irán deslizando al poeta hasta el Cancionero y los últimos poemas» (Sánchez Vidal 1992: 88). Se ha emparentado este poemario con el Guernica, que ilustra el trágico bombardeo de la ciudad sagrada vasca por el franquismo, con «una retórica vanguardista cercana al cubismo de Picasso, que, curiosamente, Miguel detestaba» (López Baralt 2010: 85); no obstante, en estas dos canciones «de auténtico origen popular, [el poeta] vuelve a las formas tradicionales de su niñez, la canción y el romance» (De Luis y Urrutia 1988: 78).

Molde retórico y tensión afectiva son dos rectas que se cruzan de modo singular a partir de estos dos poemitas, ubicados como prólogo y epílogo (resaltados en bastardilla) en este su último libro preparado para la imprenta en 1939, El hombre acecha5. La ligera musicalidad de la canción provee un basamento rítmico a una reflexión que imbrica la dimensión afectiva no solo por sus apelaciones al orbe doméstico y privado, sino por su carga política

5 Recordemos que se hallaba listo para encuadernación (entregado a fines de 1938) en una imprenta valenciana, cuando en la primavera de 1939 fueron quemados los 50.000 ejemplares por tropas franquistas; solo dos copias completas sin encuadernar se «salvaron», una de las cuales quedó en la colección de José María Cossío y del que finalmente se publicó una edición facsímil en junio de 1978 (por Leopoldo de Luis y Jorge Urrutia). El original entregado a la imprenta de Valencia está perdido. 
e histórica. No nos referimos a temáticas sentimentales, sino a una estructuración que verbaliza la fusión entre la preocupación civil y la existencial, articulando un discurso de y desde la intimidad afectiva. Serán estas dos «piezas breves, intensas y monódicas» las que lo liberan al poeta del torrente épico de su poesía de guerra (inequívocamente presente en el cuerpo central de El hombre acecha), para inaugurar el «breve, íntimo y recogido poemilla que no suele expandirse más allá del octosílabo», como bien advierte Sánchez Vidal (I993: I05).

La función paratextual de estos dos poemas de El hombre acecha (con la rúbrica ordinal de los adjetivos "primera» $\mathrm{y}$ «última») y el evidente lazo de continuidad que los une entre sí habilitan una lectura secuencial que arroja nuevas luces sobre un libro de tono fuertemente testimonial referido a los estragos de la guerra y las esperanzas militantes. Ambos poemas aparecen destacados con tipografía diferente de los demás, respondiendo a una sólida estructuración del libro (a diferencia de Viento del pueblo), y, a juzgar por los manuscritos, fueron escritos en último lugar. Por eso, no es casual el vínculo con el Cancionero y romancero de ausencias y así Sánchez Vidal puede proponer «un ciclo único que arranca de las cursivas de El hombre acecha» (I993: I05) y desemboca en la recopilación final del Cancionero (publicado póstumamente por la editorial Losada en Buenos Aires en I958). Se supone que sus fechas de redacción fueron muy próximas a las de gran parte de los poemas que conformarán después el Cancionero, pero la decisión autoral las apartó y destinó a este poemario, quizás para aminorar la carga bélica del resto de sus textos añadiendo, en lugares tan decisivos, dos canciones de neto corte popular. También Sabrina Riva en su libro concluye que esta potencia oral se intensifica en los últimos poemarios (20I7). Y, sin duda, "Canción primera», «Carta» y «Canción última» de El hombre acecha son textos bisagra que marcan la opción de Hernández por formas más breves, en consonancia con la métrica característica de la poesía oral tradicional. En el aliento breve de estas composiciones, la autora registra un cambio de tono anudado a un «repliegue sobre la intimidad, que no había aflorado aún en la obra del alicantino», excepto incipiente ya en «Canción del esposo soldado» (Riva 20I7: I70).

Estas razones se justifican si atendemos a la constante que atravesará toda su poesía: su concepción del hombre, pero también de la praxis poética, como un territorio de frontera, donde se cruzan la esfera privada y la pública, las tensiones (armónicamente conflictivas) entre emociones individuales y aspiraciones políticas. Para Leopoldo de Luis y Jorge Urrutia, estos poemas entran dentro del apartado que denominan «de aflicción», «que es el que marca la tónica del libro», pues estamos frente a «un libro de dolor y, en cierto modo, de decepciones» (1988: 33-34). Son textos que «condensan el núcleo imaginario»y «el más auténtico soporte lírico» del poemario, ya que 
«se remontan sobre la circunstancia para hablar con hondura de situaciones y vivencias de cualquier ser humano», principalmente la "escisión trágica del sujeto» (Barroso Villar 2008: 88, 97), que equipara hombre y animal.

La «Canción primera», con métrica de romance (heptasílabos con rima interna), abre la meditación central del libro con una tonalidad política y filosófica, aunque el cauce retórico establece un enlace con la vertiente intimista. Se abre con la tremenda imagen del «homo homini lupus» de Plauto (en Asinaria), que hizo suya Thomas Hobbes (en Leviatán), explicado desde el contexto histórico de producción del libro, con una clara ecuación simbólica -«hombre/animal», «fiera-tigre-garra»-. Dos campos semánticos entran en colisión: la animalización del hombre y la impotencia de su frágil humanidad. El primer proceso condena al hombre a sus instintos más violentos y lo emparienta con la ferocidad del «tigre» y sus «garras» que evoluciona en un dramático movimiento: se «abalanza» sobre «el campo» y «el olivo», «desnuda / en toda su crueldad» las «garras», otrora cubiertas de «flores», «dispuesto a hundirlas» ahora en la carne humana ${ }^{6}$. Se trata de una regresión a un estadio de elemental violencia originaria («He regresado al tigre»), que justifica la doble valencia del título («primera» alude también a esta fase antihumana primigenia, sinónimo de «primaria»). La disyuntiva («Aparta o te destrozo») desemboca en el vocablo clave de su elaboración ideológica, que equipara los términos de la disyunción: «Hoy el amor es muerte». Y hace plausible el cierre argumentativo, que recupera a modo de conclusión la dimensión filosófica del título del poemario: «y el hombre acecha al hombre». Es el «hombre-lobo» el que acecha al hombre humano cuya identidad queda pues escindida.

Pero esta humanidad amenazada recurre a la naturaleza solidaria del «campo» y el «olivo» para compensar «el abismo». El hombre se reconoce también como «animal / que canta», que "puede llorar y echar raíces», recordando una etapa donde las "garras» eran territorio «de suavidad y flores». La máxima intimidad se despliega cuando se abre el enunciado a la interlocución. El hablante es un padre que previene al «hijo» del peligro inevitable de su naturaleza: «Aparta de ellas, hijo». La lucha es inminente y las garras «crepitan en mis manos». Esta fatalidad corroe el propio sentimiento de paternidad: «Estoy dispuesto a hundirlas/ [...] sobre tu carne leve». No hay salida posible porque es el animal (no ya «el hombre») el que «acecha al hombre», vaciando el primer término de su acepción original.

Este es un libro de especial importancia en su obra, pues su contexto de producción es la Guerra Civil. El sujeto bélico mira sus propias manos convertidas en garras y, en estas canciones, más que defender ideas de lucha

6 Las citas de poemas corresponden a la edición crítica de su obra a cargo de Agustín Sánchez Vidal y José Carlos Rovira, con la colaboración de Carmen Alemany (Hernández 1992). 
o denunciar al enemigo, se des-garra por el carácter fratricida y las consecuencias devastadoras que implica. La «Canción última» adquiere renovado valor, al leerla en continuidad con la primera. Vemos un escenario opuesto: desde la salvaje «selva», donde reinaba el «hombre-tigre», nos trasladamos a la calidez de una «casa» colmada y «pintada», no «vacía», metáfora del amparo y refugio de la identidad, correlato objetivo del hombre «nuevo» que la habita. Es un pequeño universo doméstico que repone y a la vez modifica aquellas señas de identidad del «hombre-tigre», que ha regresado al «hombre-casa». Se establece un diálogo implícito con aquella canción de apertura, y el hablante comienza el moroso recuento de sus prendas recuperadas: las paredes pintadas, la mesa dispuesta, la cama con su almohada, la sábana perfumada... Se trata de un «regreso» inverso al del poema inicial (aquel «He regresado al tigre»). Aquí es la «casa pintada» la que «regresará del llanto / adonde fue llevada»; "pasiones y desgracias» le confieren una naturaleza emocional mixta. Aquella ferocidad animal puede ser al fin conjurada («será la garra suave»), porque la casa actúa como amparo eficaz («el odio se amortigua detrás de la ventana»). El presente de este personaje conserva rastros de su pasado, pero se identifica con su futuro: «Dejadme la esperanza».

La metáfora animal de la «garra», en la primera canción, era una seña del retroceso del hombre a su faz animal; en la última, es la amenaza conjurada. El oxímoron («garra suave») expresa un nuevo horizonte humano que apuesta a la «esperanza» del último verso. El tránsito desde el «llanto» social (del que «regresa») a los «besos» $\mathrm{y}$ «perfumes» de los «cuerpos» que «florecen» sella un compromiso íntimo (la «casa/cuerpo»). La esfera privada, domesticada por el amor, es como una «intensa enredadera» que lo circunda, y entrelaza sus sucesivas identidades: la «garra» («odio») hundida en el «hijo» ahora se «amortigua detrás de la ventana» y se vuelve «suave».

La tonalidad musical dirige, pues, la expectativa del lector desde la instancia paratextual, como bien se ha estudiado desde la titulogía (López Guil y Carrillo Morell 20I9). En «Canción primera», el título permite aligerar la carga revulsiva del contenido desplegado y equilibrarlo con la memoria activa que el lector repone sobre las connotaciones «líricas» y sentimentales de la tradición de este molde: «Se canta lo que se pierde», al decir machadiano. Y aquí Hernández no se engaña sobre la hondura de la pérdida que evoca su canto, tan trágica o quizás más que el corrosivo paso del tiempo al que aludía el poeta sevillano. Se ha perdido el hombre a sí mismo (devuelto al animal) y la canción se hace oportuna y necesaria. Es «primera» porque funciona como pórtico del libro, pero también porque designa la etapa primaria de la especie, que nos funde con el reino animal, marcado por la violencia irracional (como horizonte histórico y como naturaleza ingobernable del ser humano). Pero si el rótulo de «canción» busca imprimir un tono li- 
gero e íntimo a ese primer texto, activando en el lector sus resonancias más tradicionales, para compensar el fortísimo efecto corrosivo de la meditación existencial que lo preside, la «Canción última» se desembaraza de esa lógica pesimista. Nos exhibe un abanico de imágenes de una intimidad en clave simbólica, que construye una melodía esperanzada. Se canta ahora «lo que se espera», rectificando a Machado. Y lo que este hablante, adelgazado a unos imprecisos deícticos, elabora como anhelo no puede escindir su faceta plural de su naturaleza individual. Es esta voz «íntimamente social» la que tiene la última palabra de El hombre acecha -último poemario «terminado» por el autor-, que anuda la lucidez desgarrada con la canción henchida de esperanza. Aunque es también una respuesta a la experiencia de la guerra, porque dolorosamente sabe este hablante que está todo perdido y los republicanos no van a ganarla.

Un pliegue más de este giro afectivo de la canción aparece, como ya adelantamos, en otro poema de El hombre acecha titulado "Carta». Es para Sánchez Vidal «uno de los pocos textos cuyo tono y forma conecta con las dos canciones»; y los tres textos son el eslabón entre este poemario y el Cancionero posterior (I993: I05). Además del parentesco retórico (cancioneril), en un primer esbozo de esta «Carta» encontramos versos de directa relación con la «Canción primera»: «fieras peores que fieras, / también fieras nos han hecho», «mientras los colmillos crecen, / a clavarse predispuestos, / y se abalanzan los odios...» (I056-I057). La inequívoca síntesis presente en ambas canciones -la que enlaza muerte y amor, denuncia e intimismo- se reproduce en este extenso poema, que conjuga versos octosílabos y heptasílabos, hace uso directo del estribillo y evoca el tono lírico de la canción popular. Como bien señala Serna Arnaiz, se apoya «en reiteraciones y juegos conceptuales propios de los cancioneros» (I993: 689). Además, le añade una fusión interesante con el género epistolar, trasvasado al formato lírico.

La versión definitiva cifra en el emblema de la «carta» las manos de anónimas mujeres y hombres - «malheridos por la ausencia, / desgastados por el tiempo», «lanzados de sangre a sangre»-, que escriben como el hablante: «cuando te voy a escribir, / te van a escribir mis huesos: / te escribo con la imborrable / tinta de mi sentimiento» (Hernández I992: 397). Si las cartas «perecen» olvidadas y no llegan a destino, «el papel se agujerea / como un breve cementerio» (396), pero la muerte no las anula y persisten: «cartas que se quedan vivas / hablando para los muertos» (397). En el molde de un poema amoroso, cuyo estribillo insiste en la sobrevida del cuerpo enamorado («Aunque bajo la tierra / mi amante cuerpo esté, / escríbeme a la tierra / que yo te escribiré»), el poema revierte la fatal sentencia de la «Canción primera», que proclamaba «Hoy el amor es muerte». Aquí, en sintonía con la «Canción última», las «heridas» serán «derramados tinteros» y las «bocas 
estremecidas» rememorarán los «besos», «y con su inaudita voz / han de repetir: te quiero» (398).

Por otro lado, la famosa «Canción del esposo soldado» de Viento del pueblo resulta ser un antecedente ideológico decisivo de estas dos canciones aquí analizadas por el uso explícito de imágenes emparentadas, además de la insistencia en el molde desde el título: «Y dejaré a tu puerta mi vida de soldado / sin colmillos ni garras» (360). «Matar» / «vivir», el «hijo» y la «sábana», la lucha «desde la brecha» y el «camino de besos implacables» son motivos que enhebra esta canción y prefiguran el itinerario de una semiosis poética liberada de su cronología textual: «Es preciso matar para seguir viviendo». Aunque reconoce: «Para el hijo será la paz que estoy forjando» (36I).

Coincidimos con Serge Salaün cuando defiende la validez de «una lectura afectiva, una lectura ideológica y una lectura estética» simultánea en estos poemas hernandianos, pues la suya es una poética de un «materialismo militante», que anuda «la sensación con la inteligencia dentro del acto verbal mismo», apuesta a la eficacia comunicativa del signo y a su «rentabilidad semántica» (I993: I05). No hay duda de que aun en este poemario catalogado «de guerra» con un «discurso épico», «cabe el individuo y la comunidad entera, el yo íntimo y el otro», al punto tal que no parece exagerada su conclusión final: «Hernández es uno de los creadores que mejor resolvieron el problema de la traducción de la ruptura estética en ruptura social y política, el que mejor materializó un humanismo superior» (Salaün I993: II3). Y el famoso cantautor, que dedicó parte de su discografía a homenajearlo, no lo puede afirmar mejor: «Si no le hubiera gustado que sus poemas olieran a canción, no existiría una «Canción del esposo soldado», ni una «Canción primera», ni una "Canción última» (Serrat 20I0: 130)7 La elección paratextual es, pues, ya de por sí un compromiso que gravita en su aguda consciencia autopoética (Scarano 20I7).

\section{Bibliografía}

AA. VV., Miguel Hernández, cincuenta años después. Actas del I Congreso Internacional, Alicante, Comisión del Homenaje a Miguel Hernández, I993, https://dialnet.unirioja.es/servlet/libro?codigo=5I9432 [I2.II.2020].

Aullón de Haro, Pedro, «Las ideas teórico-literarias de Miguel Hernández», en AA. VV., Miguel Hernández, cincuenta años después. Actas del I Congreso Internacional, Alicante, Comisión del Homenaje a Miguel Hernández,

7 Joan Manuel Serrat dedica un disco homenaje al oriolano en 1972 -Miguel Hernández-, con textos que pertenecen en su mayoría al ciclo compositivo final del poeta. Durante el centenario del nacimiento de Hernández en 20Io, el cantautor registró un segundo disco con versiones de poemas hernandianos, denominado Hijo de la luz y de la sombra. 
I993, pp. 259-27I, https://dialnet.unirioja.es/servlet/libro?codigo=519432 [I2.II.2O2O].

Barroso Villar, $\mathrm{M}^{\mathrm{a}}$. Elena, «El hombre acecha e imaginario artístico de la violencia. La escisión trágica del sujeto», Anthropos, 2008, pp. 88-99.

Barthes, Roland, Ensayos críticos, Barcelona, Seix Barral, I967.

Bousoño, Carlos, «Notas sobre un poema de Miguel: "Antes del odio"», Ágora, 49-50, 1960, pp. 33-35.

Cano Ballesta, Juan, «Miguel Hernández y el debate cultural de los años treinta», AA. VV., Presente y futuro de Miguel Hernández. Actas II Congreso Internacional Hernandiano, Orihuela, Fundación Cultural Miguel Hernández, 2003, pp. I2I-I38, https://dialnet.unirioja.es/servlet/articulo?codigo=647IO93 [I2.II.2020].

Del Sarto, Ana, «Los afectos en los estudios culturales latinoamericanos. Cuerpos y subjetividades en Ciudad Juárez», Cuadernos de literatura, 32, Julio-Diciembre, 20I2, pp. 4I-68.

Frenk, Margit, Poesía popular hispánica: 44 estudios, México, FCE, 2006.

Hernández, Miguel, Obra poética completa, intr., estudios y notas Leopoldo de Luis y Jorge Urrutia, Madrid, Alianza, 1982.

- El hombre acecha/Cancionero y romancero de ausencias, eds., Leopoldo de Luis y Jorge Urrutia, Madrid, Cátedra, I988.

- Obra completa. Poesía, 2 tomos, eds. Agustín Sánchez Vidal \& José Carlos Rovira (con la colaboración de Carmen Alemany), Madrid, Espasa Calpe, 1992 .

Jakobson, Roman, Lingüística y poética, Madrid, Cátedra, I98I.

Lamberti, Marapia, «La evolución métrica en la poesía de Miguel Hernández», en AA. VV., Miguel Hernández, cincuenta años después. Actas del I Congreso Internacional, Alicante, Comisión del Homenaje a Miguel Hernández, I993, II, pp. 669-667.

Leuci, Verónica, «La canción y sus múltiples rostros genéricos», Espéculo, 42, 2009, s/p.

López Baralt, Mercedes, «Tradición y vanguardia: las fuentes múltiples de Miguel Hernández», Miguel Hernández [exposición]: la sombra vencida, I9IO-20IO, coords. José Carlos Rovira Soler \& Carmen Alemany Bay, Vol. I, 20Io, pp. 79-89, http://www.bne.es/es/Micrositios/Exposiciones/miguel_hernandez/documentos/estudios_07_baralt.pdf [I2.II.2020].

López Guil, Itzíar \& Dayron Carrillo Morell (eds.), El título del poema: sus efectos en el texto lírico iberoamericano contemporáneo. Homenaje al Prof. Dr. Georges Güntert en su 80 cumpleaños, Berna, Peter Lang, 2019.

Marco, Joaquín, «Función y ficción del poeta en la poesía de guerra de Miguel Hernández», en AA. VV., Miguel Hernández, cincuenta años después. Actas del I Congreso Internacional, Alicante, Comisión del Homenaje a Miguel Hernández, I993, II, pp. I39-I46. 
Puccini, Darío, «Miguel Hernández, la formación del poeta civil», en AA. VV., Miguel Hernández, cincuenta años después. Actas del I Congreso Internacional, Alicante, Comisión del Homenaje a Miguel Hernández, I993, I, pp. II5-I2I.

Riva, Sabrina. «Flotando en el viento. Miguel Hernández y la canción de autor española", en Variaciones de lo metarreal en la España de los siglos XX y XXI, eds. B. Greco y L. Pache Carballo, Madrid, Biblioteca Nueva, 20I4, pp. 389-399.

-. «Verdades cansadas. Miguel Hernández y la construcción de su figura como escritor "popular"», en Actas de las Jornadas Internas de Investigadores en Formación del Departamento de Letras, Universidad Nacional de Mar del Plata, 20I5, pp. 327-334.

- La garra suave: representaciones de Miguel Hernández como escritor popular, Salamanca, Ediciones Universidad de Salamanca, 2017.

Rivera, Jorge \& Aníbal Ford, «La canción popular», Capítulo Universal. La historia de la Literatura mundial, No 38, Buenos Aires, CEAL, I97I, pp. 7376.

Rovira, José Carlos, «Configuraciones imaginativas y su evolución en el texto», en AA. VV., Miguel Hernández, cincuenta años después. Actas del I Congreso Internacional, Alicante, Comisión del Homenaje a Miguel Hernández, I993, I, pp. 20I-207.

Salaün, Serge, «Miguel Hernández, hacia una poética total», en AA. VV., Miguel Hernández, cincuenta años después. Actas del I Congreso Internacional, Alicante, Comisión del Homenaje a Miguel Hernández, I993, I, pp. IO5-II3.

—. «La poesía de la guerra de Miguel Hernández. Una poética de la voz y la dicción», Ínsula, 763-764, Julio/Agosto, 20I0, pp. I9-2I.

Sánchez Vidal, Agustín, «Introducción», en Miguel Hernández, Obra completa. Poesía, Madrid, Espasa Calpe, I992, Tomo I, pp. 27-II6.

—. «Para una revisión de Miguel Hernández», en AA. VV., Miguel Hernández, cincuenta años después. Actas del I Congreso Internacional, Alicante, Comisión del Homenaje a Miguel Hernández, I993, I, pp. 99-II3.

- - "Imágenes para un poeta», en AA. VV., Presente y futuro de Miguel Hernández: actas del II Congreso Internacional Miguel Hernández, 2004, pp. IO7I20, https://dialnet.unirioja.es/servlet/libro?codigo=7I3695 [I2.II.2020].

Scarano, Laura, Marcar la piel del agua. La autorreferencia en la poesía española contemporánea, Rosario, Beatriz Viterbo Ed., I996.

-. (ed.) Palabras en el cuerpo. Literatura y experiencia, Buenos Aires, Biblos, 2007 .

-. «Identidad social e intimidad sentimental en las canciones de El hombre acecha de Miguel Hernández», Canelobre, 56, Invierno, 20ıo, pp. I46-I6I. 
—. «Intimidades de papel (La escritura poética del yo íntimo)», Telar. Revista del Instituto Interdisciplinario de Estudios Latinoamericanos, 9, VII, 20II, pp. I5-3I.

-. (ed.) La poesía en su laberinto. AutoRepresentacioneS\#I, Binges, Editions Orbis Tertius, 2013.

—. «Escribo que escribo: de la metapoesía a las autopoéticas», Tropelías. Revista de Teoría de la Literatura y Literatura Comparada, 2, 20I7, pp. I33-I52.

Scarano, Laura, Romano, Marcela \& Marta Ferrari, La voz diseminada. Hacia una teoría del sujeto en la poesía española, Buenos Aires, Biblos, I994.

Serna Arnaiz, Mercedes, «Formas tradicionales en la poesía de Miguel Hernández: el romance y la copla», en AA. VV., Miguel Hernández, cincuenta años después. Actas del I Congreso Internacional, Alicante, Comisión del Homenaje a Miguel Hernández, I993, II, pp. 687-692.

Serrat, Joan Manuel, «Miguel Hernández y la canción», Barcarola, 76, 2010, pp. I29-I3I, https://elpais.com/diario/2010/03/o7/eps/I2679468I4_850215. html [I2.II.2020].

Suárez Miramón, Ana, «El Cancionero de Miguel Hernández y su inserción en los cancioneros del siglo XX», en AA. VV., Miguel Hernández, cincuenta años después. Actas del I Congreso Internacional, Alicante, Comisión del Homenaje a Miguel Hernández, I993, II, pp. 635-645. 
